\title{
Associated Pulmonary Arterial Hypertension
}

National Cancer Institute

\section{Source}

National Cancer Institute. Associated Pulmonary Arterial Hypertension. NCI Thesaurus.

Code 197147.

Pulmonary hypertension that results from another disorder (e.g., connective tissue disorder). 